\title{
RETÓRICA, CRÍTICA LITERARIA Y CANON EN QUINTILIANO, INSTITUTIO ORATORIA 10.1
}

\author{
Verónica Iribarren · Melina Jurado \\ Universidad de Buenos Aires \\ veronicairibarren@gmail.com \\ melinajurado@gmail.com
}

El canon literario implica un proceso de selección sistemático y jerárquico de escritores, obras y géneros con el fin de delimitar un corpus modélico imitable ligado fuertemente a la instrucción pedagógica. En el presente trabajo se analizará el particular proceso de formación y conformación del canon -así como su recepción y transformación respecto de los cánones previos- establecido por Quintiliano en el Libro 10 de la Institutio Oratoria, a fin de demostrar que los criterios de selección que guían dicho canon exceden la mera función didáctica.

retórica / crítica literaria / Quintiliano / canon / fuentes

\section{RETHORIC, LITERARY CRITICISM AND CANON IN QUINTILIAN, INSTITUTIO ORATORIA 10.1}

The literary canon implies a systematic and hierarchic selection of writers, works and genres in order to delimit an imitable model corpus connected to the pedagogic instruction. This paper analyzes the particular process of formation and conformation of the canon -as well as its reception and transformation from previous canons- established by Quintilian in the Book 10 of his Institutio Oratoria, in order to demonstrate that the criteria of selection that guide the canon exceed the mere didactic function.

rethoric / literary criticism / Quintilian / canon / sources 


\section{Preliminares}

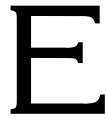

nmarcado en la línea de los recientes estudios de teoría literaria, así como en el cuadro de renovación teórica surgido en el campo de la filología clásica (que ofrece una interesante reflexión acerca de la práctica de la escritura y la configuración de la historia literaria en la Antigüedad), el presente trabajo tiene como propósito la problematización de las nociones de canon, tradición e historia literaria en la cultura latina de fines del siglo I d. C., específicamente en la obra retórica de $M$. Fabio Quintiliano. La Institutio Oratoria, en general, así como el canon del libro 10.1, en particular, presentan un gran interés para la historia y la crítica literaria posteriores, así como para la cultura y la literatura occidental, constituyéndose en modelo fundamental para oradores, gramáticos, filólogos y pedagogos, tal como para poetas o teorizadores del arte ulteriores. Asimismo, dado que el rétor menciona y ofrece en reiteradas oportunidades su propio juicio acerca de textos literarios greco-romanos de autores cuyas obras no conservamos en la actualidad, se torna una fuente textual clave para su conocimiento.

De acuerdo con la crítica, todo canon se presenta como una estructura histórica cambiante dependiente del sujeto ideológico, individual y colectivo que lo postula ${ }^{1}$. Sometido a las oscilaciones del devenir histórico, así como a los diversos supuestos ideológicos y criterios estético-retóricos imperantes en una determinada época y cultura, el canon literario implica un proceso intencional de selección sistemático y jerárquico de escritores, obras y géneros transmitidos por la tradición, con el fin de delimitar un corpus modélico imitable ligado fuertemente a la instrucción pedagógica. Según R. Williams², “... lo que debemos entender no es precisamente 'una tradición', sino una tradición selectiva: una versión intencionalmente selectiva de un pasado configurativo y de un presente preconfigurado, que resulta entonces poderosamente operativo dentro del proceso de definición e identificación cultural y social". De acuerdo con este autor, la tradición (en nuestro caso, la literaria) es una versión del pasado (una selección de significados y prácticas) que se pretende conectar con el presente y ratificar un sentido de predispuesta continuidad.

1 SULLÁ (1998: 30).

2 Williams (1980: 137-138). Cabe aclarar que Williams aquí se contrapone a los planteos tradicionales del marxismo clásico que consideraban 'la tradición' como una supervivencia inerte del pasado. Para una reflexión, basada en el concepto de "tradición selectiva" planteado por Williams, en torno a la relación política y teórica establecida por Quintiliano en el libro 10 de la Institutio Oratoria entre el pasado literario y la regulación de la práctica intelectual de la retórica, cf. Fernández - MARELLo (2010). 
Así pues, todo canon y, por ende, toda historia literaria que se desprenda de él, entraña una retrospección y recuperación significativa del pasado, que se adecua al presente, esto es, a los intereses particulares del sujeto que los configura, adquiriendo de esta forma un nuevo valor en un contexto histórico dado. En este sentido, debemos tener en cuenta la complejidad de la actividad cultural y considerar la tradición y la historia literarias como algo dinámico y abierto a la apropiación. Como sostiene Hinds, ${ }^{3}$ la propia recepción de los textos canónicos transmitidos en la Antigüedad (basada en los conceptos de auctoritas y utilitas, así como en el principio de la imitatio) desestabiliza el pretendido control normativo y objetivo ejercido por la tradición y la historia literarias, dependientes de una institución identificable, por el hecho de que estas están en competencia con otras historias literarias construidas por otros escritores y lectores a través del continuum temporal, y con otro tipo de formaciones ${ }^{4}$ emergentes.

En el primer capítulo del libro 10 de la Institutio Oratoria, Quintiliano elabora como parte de su programa educativo ${ }^{5}$ un canon de autores que, por su excelencia lingüística y estilística, considera modélicos, esto es, dignos de ser imitados. En consonancia con las consideraciones teóricas anteriormente expuestas, consideramos, a modo de hipótesis, que el rétor no ha reproducido pasivamente una tradición canónica anterior, ni ha buscado fundir dos o más preceptivas ponderadas, sino que ha creado un canon propio y original, atravesado por diversas tendencias críticas, especialmente por aquellas vigentes en el momento de su composición. La jerarquización de autores fijada en el listado modélico no se limita a la finalidad didáctica, sino que persigue también fines especulativos, relacionados fuertemente con los intereses literarios de Quintiliano, que lo llevan a formular por doquier algunas reglas generales y preceptos teóricos de crítica literaria.

Para comprobar dicha hipótesis, nos abocaremos al análisis diacrónico y pormenorizado del proceso de conformación de dicho canon, a fin de caracterizar el modelo de historia literaria que conlleva. Para ello, confrontaremos, en primer lugar, el canon del libro 10 con otros pasajes de la obra, para luego recabar en la singular posición del rétor respecto de la

3 Hinds (1998: 143-144).

4 Nos referimos al concepto de formaciones de Williams (1980: 139-141), es decir, las tendencias y movimientos conscientes (literarios, artísticos, filosóficos o científicos) en la vida intelectual y artística, que tienen una influencia significativa y a veces decisiva sobre el desarrollo activo de una cultura y que presentan una relación variable y a veces solapada con las instituciones formales.

5 Su obra posee como objetivo central la formación del orador ideal y, por lo tanto, la selección cuidadosa de todos aquellos conocimientos y lecturas que contribuyan a su instrucción retórica. 
configuración de dicho canon. Esto nos llevará a detectar ciertas diferencias, contradicciones e incongruencias en el proceso particular de selección (inclusión o exclusión de determinados autores y géneros discursivos) que el autor opera sobre la tradición retórico-literaria griega y romana. Por último, compararemos el canon de Quintiliano con cánones de escritores anteriores (griegos y romanos) y contemporáneos (Séneca, Marcial), que pueden haber influido en él, establecidos desde supuestos ideológicos y estéticos diferentes; todos ellos aspectos aún no abordados en profundidad por la crítica clásica actual.

\section{El canon en contexto}

Para llevar a cabo este objetivo, debemos tener en cuenta en primer lugar que no puede separarse el canon del libro 10 del resto de la obra, a lo largo de la cual hallamos menciones de numerosos autores y diversas consideraciones acerca de los géneros literarios. En efecto, este canon es la culminación de un largo recorrido que comienza cuando el niño, futuro estudiante de oratoria, aprende las primeras letras. A propósito de esta primera etapa educativa, ya en el libro 1 de la Institutio Oratoria Quintiliano se expresa acerca de la utilidad que ofrece cada género literario a fin de preparar la mente del joven para los estudios superiores. Según el autor, debe privilegiarse la épica (sublimitate heroi carminis, 1.8.5) y el género dramático (utiles tragoediae... comoediae, 1.8.6-7) por sobre la lírica, solo habilitada para los adultos a raíz de su contenido (1.8.6). Frente a la sublimitas de la épica y la utilitas del teatro, la lírica se presenta como indecens y, si bien no se prohíbe su lectura en una edad más avanzada, nada se dice acerca de sus aportes para la formación oratoria, quizá por considerárselo un género ligado al esparcimiento.

Ahora bien, si efectuamos un recorrido por los libros 1 a 9, podemos reconstruir una nómina de autores mencionados y citados reiteradamente: Homero, Virgilio, Livio, Horacio, Demóstenes, Isócrates, Cicerón y Platón ocupan los primeros puestos; los siguen Aristóteles, Menandro, Terencio y Polión. Todos ellos son muy valorados en el canon, lo cual demuestra la coherencia de la obra de Quintiliano en su totalidad. Por otra parte, se anticipan críticas a algunos escritores: Pacuvio (1.5.67), Éforo (2.8.11), Lisias (9.4.17), Domicio Afro (9.4.31), Lucilio (1.passim). No obstante, este criterio -hasta aquí congruente- se ve perturbado por algunos detalles. En primer lugar, constantemente Quintiliano cita tratados retóricos anteriores y ejemplos de oradores, la mayoría de los cuales ignora en el canon del 
libro $10 .{ }^{6}$ Asimismo, varias veces utiliza como citas de autoridad a Enio, Catulo, Ovidio o Accio, ${ }^{7}$ escritores que en el canon aparecen devaluados. Por el contrario, reprocha algunos pasajes de Horacio (1.8.6.) y el estilo de Teopompo (2.8.11), o la breuitas salustiana (2.5.19 y otros), ${ }^{8}$ quienes en el libro 10 son escritores alabados. Finalmente, géneros menores, que son completamente apartados del canon, se cuelan anecdóticamente y sin desdeño?.

Cuadro 1: Quintiliano: canon de poetas

\begin{tabular}{|c|c|c|c|c|}
\hline \multirow{2}{*}{$\begin{array}{l}\text { Género y } \\
\text { subgénero }\end{array}$} & \multicolumn{2}{|c|}{ Autores griegos } & \multicolumn{2}{|c|}{ Autores romanos } \\
\hline & + & - & + & - \\
\hline $\begin{array}{l}\text { Hexámetros } \\
\text { (épica, poesía } \\
\text { didáctica y } \\
\text { bucólica) }\end{array}$ & 5.Apolonio & $\begin{array}{l}\text { 3.Antímaco } \\
\text { 4.Paniasis } \\
6 \text {.Arato } \\
\text { 7.Teócrito } \\
\text { 8.Pisandro } \\
\text { 9.Nicandro } \\
\text { 10.Euforión } \\
11 \text { Tirteo }\end{array}$ & $\begin{array}{l}\text { 1.Virgilio } \\
\text { 13.Lucano }\end{array}$ & $\begin{array}{l}\text { 2.Macro } \\
\text { 3.Lucrecio } \\
\text { 4.Varrón At. } \\
\text { 5.Ennio } \\
\text { 6. Ovidio } \\
\text { 7. Cornelio Sev. } \\
\text { 8.Serrano } \\
\text { 9.Valerio Flaco } \\
\text { 10.Saleyo } \\
\text { Basso } \\
\text { 11.Rabirio } \\
\text { 12.Pedón } \\
\text { 14.Domiciano }\end{array}$ \\
\hline Elegía & $\begin{array}{l}\text { 1.Calímaco } \\
\text { (princeps) }\end{array}$ & 2.Filetas & 1.Tibulo & $\begin{array}{l}\text { 2.Propercio } \\
\text { 3.Ovidio } \\
\text { 4.Galo }\end{array}$ \\
\hline
\end{tabular}

6 Por ejemplo, Calvo, Hortensio, Q. Cátulo, Mecenas o Cornelio Celso. Con todo, recupera a algunos de estos autores en una suerte de segundo canon solamente de oradores que lleva a cabo en el libro 12.

7 En el libro 10, Accio es censurado al igual que el resto de los escritores arcaicos. Sin embargo, en 5.13.43 paradójicamente se le otorga fuerza oratoria.

Cf. también Quint., Inst. 4.2.45, 8.3.29, 10.1.32 y 10.2.17. Esta concepción negativa en relación con este rasgo particular del estilo salustiano -que, según el calagurritano, lo haría caer en la obscuritas-, se transforma en el canon del libro 10, ya que el rétor desea destacar a Salustio y especialmente a Tito Livio, a quien se adjudican ciertos rasgos de estilo similares al primero, por sobre los demás historiadores. En consecuencia, y estratégicamente, la breuitas salustiana es presentada como una virtud con el nombre de uelocitas (101.102). Se elogia a Sofrón, autor de mimos (1.10.17), se ejemplifica con el fabulista Esopo (1.9.2 y 5.11.19), se define la silva como género de improvisación (10.3.17), y se citan dos epigramas (1.5.21 y 8.3.29) 


\begin{tabular}{|c|c|c|c|c|c|}
\hline \multicolumn{2}{|c|}{ Sátira } & -- & -- & $\begin{array}{l}\text { 2.Horacio (prae- } \\
\text { cipuus) }\end{array}$ & $\begin{array}{l}\text { 1.Lucilio } \\
\text { 3.Persio } \\
\text { 4.Varrón R. }\end{array}$ \\
\hline \multicolumn{2}{|c|}{ Yambo } & Arquíloco & -- & $\begin{array}{l}\text { 1.Catulo } \\
\text { 2.F. Bibáculo }\end{array}$ & 3.Horacio \\
\hline \multicolumn{2}{|c|}{ Lírica } & $\begin{array}{l}\text { 1.Píndaro } \\
\text { 3.Alceo } \\
\text { 4.Simónides }\end{array}$ & 2.Estesícoro & 1.Horacio & 2.Cesio Basso \\
\hline \multirow{3}{*}{ 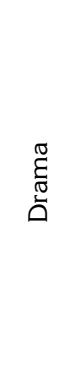 } & $\begin{array}{l}\text { Comedia } \\
\text { antigua }\end{array}$ & $\begin{array}{l}\text { 1.Aristófanes } \\
\text { 2.Éupolis } \\
\text { 3.Cratino }\end{array}$ & -- & -- & -- \\
\hline & Tragedia & $\begin{array}{l}\text { 2.Sófocles } \\
\text { 3.Eurípides } \\
\text { (melior) }\end{array}$ & 1.Esquilo & $\begin{array}{l}\text { 3.Vario } \\
\text { 5.Pomponio } \\
\text { Seg. (princeps) }\end{array}$ & $\begin{array}{l}\text { 1.Accio } \\
\text { 2.Pacuvio } \\
\text { 4.Ovidio }\end{array}$ \\
\hline & $\begin{array}{l}\text { Comedia } \\
\text { (nueva) }\end{array}$ & 1.Menandro & 2.Filemón & $\begin{array}{l}\text { 3.Terencio } \\
\text { (scripta elegan- } \\
\text { tissima) }\end{array}$ & $\begin{array}{l}\text { 1.Plauto } \\
\text { 2.Cecilio } \\
\text { 4.Afranio }\end{array}$ \\
\hline
\end{tabular}

Cuadro 2: Quintiliano: canon de autores en prosa

\begin{tabular}{|c|c|c|c|c|}
\hline \multirow{2}{*}{ Género } & \multicolumn{2}{|l|}{ Autores griegos } & \multicolumn{2}{|c|}{ Autores romanos } \\
\hline & + & - & + & - \\
\hline Historia & $\begin{array}{l}\text { 1.Tucídides } \\
\text { 2.Heródoto } \\
\text { 3.Teopompo }\end{array}$ & $\begin{array}{l}\text { 4.Filisto } \\
\text { 5.Éforo } \\
\text { 6.Clitarco } \\
\text { 7.Timágenes } \\
\text { 8.Jenofonte }\end{array}$ & $\begin{array}{l}\text { 1.Salustio } \\
\text { 2.Tito Livio } \\
\text { (eloquentem) }\end{array}$ & $\begin{array}{l}\text { 3.Ser. Noniano } \\
\text { 4.Aufidio Basso } \\
\text { 5.F. Rústico? } \\
\text { 6.Cremucio }\end{array}$ \\
\hline Oratoria & 1.Demóstenes & $\begin{array}{l}\text { 2.Esquines } \\
\text { 3.Hipérides } \\
\text { 4.Lisias } \\
\text { 5.Isócrates } \\
\text { 6.Demetrio Fal. }\end{array}$ & $\begin{array}{l}\text { 1.Cicerón } \\
\text { 4.César }\end{array}$ & $\begin{array}{l}\text { 2.Asinio Polión } \\
\text { 3.Messala } \\
\text { 5.Celio } \\
\text { 6.Calvo } \\
\text { 7.S. Sulpicio } \\
\text { 8. Casio Severo } \\
\text { 9.Domicio Afro } \\
\text { 10.Julio Africano } \\
\text { 11.Tracalo } \\
\text { 12.Vibio Crispo } \\
\text { 13.Julio Segundo }\end{array}$ \\
\hline
\end{tabular}




\begin{tabular}{|c|c|c|c|c|}
\hline Filosofía & $\begin{array}{l}\text { 1.Platón } \\
\text { 2.Jenofonte } \\
\text { 3.socráticos } \\
\text { 4.Aristóteles } \\
\text { 5.Teofrasto }\end{array}$ & $\begin{array}{l}\text { 6.antiguos } \\
\text { estoicos }\end{array}$ & $\begin{array}{l}\text { 1.Cicerón } \\
\text { 2.Bruto } \\
\text { 3.Cornelio Celso }\end{array}$ & $\begin{array}{l}\text { 4.Plauto } \\
\text { (estoico) } \\
\text { 5.Cacio } \\
\text { (epicúreo) } \\
\text { 6.Séneca }\end{array}$ \\
\hline
\end{tabular}

A partir de estas observaciones, podemos deducir que el orador hispano maneja un compendio de autores mucho más amplio que el que enumera en el libro 10, lo cual nos remite precisamente a una de las ideas relacionadas fuertemente con el concepto de canon enunciadas al comienzo de este trabajo: el proceso de recorte o selección que todo canon implica en virtud de sus particulares objetivos, incluso al interior de una misma obra. En este caso, el objetivo sería la formación del estudiante de retórica, que debe nutrirse a partir de la frecuentación juiciosa (iudicium) de los mejores escritores. Sin embargo, las aparentes contradicciones que se deslizan en los juicios emitidos por el rétor a lo largo de la Institutio Oratoria -sumadas a otras que analizaremos dentro del libro 10- anticipan uno los aspectos sobre el que volveremos infra: el hecho de que la jerarquía de autores fijada en el listado modélico excede los fines didácticos del autor.

\section{El Libro 10 de la Institutio Oratoria}

En los primeros parágrafos de 10.1 , se retoma la temática de la utilidad de los géneros para la retórica. En este caso, la clasificación aristotélica que distinguíamos en el libro 1 se amplía con géneros en prosa, como la historia y la filosofía. Por su parte, la épica, el drama y la lírica aparecen fusionados simplemente como lectio poetarum. De estos géneros en verso -y a pesar de que se enfrentan a la retórica porque su objetivo es el placer (uoluptas)- se rescata:

Plurimum dicit oratori conferre Theophrastus lectionem poetarum multique eius iudicium secuntur; neque inmerito: namque ab his in rebus spiritus et in uerbis sublimitas et in adfectibus motus omnis et in personis decor petitur... $(10.1 .27)^{10}$.

Teofrasto dice que al orador le ofrece gran beneficio la lectura de los poetas, y muchos siguen su criterio, no sin razón. En efecto, de estos se

$\overline{10}$ Todas las citas de Quintiliano están tomadas de la edición de Winterbottom (1992). Las traducciones son nuestras. 
obtiene, en cuanto a los temas, inspiración y, en cuanto a las palabras, sublimidad y, respecto de los afectos, todas las emociones y, de los caracteres, el encanto...

En esta cita, los sustantivos sublimitas y decor ${ }^{11}$ hacen referencia claramente a los géneros elevados como la épica y la tragedia (señalada esta también por el vocablo personis y por la frase in adfectibus motus). Este es un ejemplo del hecho de que es necesario tener presente la obra en su conjunto: aunque no lo dice explícitamente, aquí Quintiliano estaría dejando de lado nuevamente la lírica. Esta es una de las contradicciones más fuertes, ya que a partir del rechazo del que es objeto este género desde el libro 1 y en virtud de la finalidad didáctica, se esperaría, en consecuencia, no hallar representada la lírica en el listado de autores modélicos. No obstante, veremos que no son pocos los autores líricos que figuran en el canon.

Respecto de los géneros prosaicos, critica la historia ya que a ella le interesa relatar (narrare), no demostrar (probare), y porque persigue memoriam posteritatis et ingenii famam (10.1.31). Es decir, a la oratoria se opondrían tanto la poesía como la historiografía respecto de la preocupación por la forma, lo cual podría afectar el adecuado tratamiento de los contenidos. En contrapartida, valora de esta su estilo brillante (nitor) y el hecho de que provee de cognitio rerum exemplorumque. Por último, la filosofía se torna necesaria para la oratoria en lo que respecta a la formación moral del orador.

Parece, entonces, muy acotado lo que cada uno de estos géneros puede aportar al estudiante de retórica. Sin embargo, todo texto contribuye a la adquisición de una cultura general y de la facilidad de palabra (facilitas), sin la cual el orador no podrá conducir ningún discurso, aunque posea un brillante conocimiento teórico. La forma de obtener la facilitas es a través de la imitación ${ }^{12}$. Es esta, pues, la razón por la cual el rétor se ve obligado a realizar en el libro 10 de la Institutio Oratoria un listado de aquellos autores que deben ser leídos atentamente e imitados por el futuro orador, a fin de fortalecer y mejorar su capacidad expresiva. Con todo, el propio Quintiliano se anticipa a posibles polémicas y realiza una serie de aclaraciones al lector. Así, expresa que él no es el primero que intenta una empresa como esta y menciona a propósito el Brutus de Cicerón. No obstante, se distancia de este tratado cuando afirma que no será tan exhaustivo como Marco Tulio. En efecto, no podrá desarrollar con tanto detalle a cada autor, dado que el rétor pretende incluir a oradores pero también a filósofos,

11 Contrástese con las citas de 1.8 mencionadas en el apartado 2.

12 Cf. Quint., Inst. 10.1.8, 44 y 59. El canon se presenta como preámbulo a su teoría retórica de la imitatio desarrollada en 10.2, donde define con detenimiento el modo en que dichos modelos deben ser utilizados por el futuro orador. 
historiadores y poetas, tanto griegos como latinos. En consecuencia, no buscará agotar cada género, sino que deberá dejar de lado a muchos escritores de méritos similares a los nombrados, y de alguno de ellos mencionará solo ciertas composiciones ${ }^{13}$. De esta forma, el problema de la extensión del canon lo lleva a afiliarse a la opinión de Tito Livio de que hay que leer únicamente a los mejores escritores y a aquellos que más se parecen a estos. Quintiliano adopta, pues, una posición singular respecto de cómo configurará su canon: en primer lugar, decide elaborar una historia literaria -es decir, acoge el criterio de Cicerón-, puesto que lejos de construir un catálogo o una mera cronología, acompaña cada nombre con un comentario acerca de su estilo (del mismo modo que el arpinate hizo en el Brutus). A fin de respetar la finalidad didáctica, dicho comentario tenderá a destacar en cada autor su principal excelencia en lo que respecta al ámbito retórico (praecipua uirtus, 10.1.37), aunque esto no siempre se cumplirá. En segundo lugar, el ordenamiento de los escritores será jerárquico (señalando al mejor y al peor), no cronológico, como se acostumbraba en tratados anteriores.

Veamos a continuación cómo organiza Quintiliano el canon en 10.1. En primera instancia, el autor menciona los modelos griegos que conforman la lista y seguidamente los latinos. Toma los géneros tradicionales de mayor prestigio y para cada uno especifica la mayor o menor contribución (utilitas) para la formación del orador; en cambio, deja de lado los géneros considerados menos prestigiosos ${ }^{14}$ (epigrama, fábula, novela, mimo):

Sed nunc genera ipsa lectionum, quae praecipue conuenire intendentibus ut oratores fiant existimem, persequor (10.1.45).

Pero ahora me dedico a los géneros mismos de lecturas que considero convienen especialmente a quienes tienen la intención de ser oradores.

El orador hispano comienza con el abordaje de los géneros compuestos en hexámetros, de la lírica y del género dramático, y continúa con la historia, la oratoria y, finalmente, con la filosofía (para más detalle, véanse supra los cuadros 1 y 2). Respecto de los poetas, se destaca una utilidad oratoria mayormente en los escritores griegos -menciona una decena de juicios positivos, lo que equivale a casi el $50 \%$ del total de autores ${ }^{15}-$ frente

${ }^{13}$ Por ejemplo, aunque alude a la invectiva de Catulo, sus composiciones líricas no son mencionadas, o se ignora el talento trágico de Séneca. Cf. LAIRD (2006: 16).

14 Cf. Citroni (2006: 4) y Pociña (1981-2: 99).

15 Señalamos aquí solo a algunos de esos autores y añadimos los juicios que los acompañan a fin de que pueda observarse su interés para la formación del orador: Homero (omnibus eloquentiae partibus exemplum et ortum;... nec poetica modo sed oratoria uirtute 
a los latinos, entre quienes se cuentan solo Virgilio, Horacio y Lucano ${ }^{16}$-es decir, sólo un $9 \%$ de los autores latinos. Así pues, Quintiliano otorga una ingente importancia didáctica a los géneros poéticos, especialmente a la épica y al drama complementados quizás por el yambo y la sátira a causa de su carácter moral. La lírica se encuentra bien posicionada respecto de los griegos; en cambio, a pesar de que se nombra a muchos poetas romanos reconocidos, quedan prácticamente todos excluidos de la finalidad formadora o retórica.

En cuanto al resto de los géneros, se reitera la preeminencia griega, no solo en la cantidad de autores aludidos, sino también en la densidad de los juicios formulados, que tienden a alentar a los futuros oradores a leerlos y emularlos. Nuevamente, solo tres escritores romanos aportan utilitas retórica, entre los que, por supuesto, se encuentra Cicerón -cuyo nombre es prácticamente sinónimo de 'elocuencia' (iam non hominis nomen sed eloquentiae habeatur, 10.1.112)-, secundado por Julio César, al que se valora como orador, no como historiador ${ }^{17}$. Para este último género, el principal autor destacado es Tito Livio (10.1.101).

De lo anteriormente expuesto, se desprende el hecho de que Quintiliano no ha podido sustraerse a la tradición de contemplar con admiración los modelos griegos y de establecer correspondencias comparativas entre la producción romana y la griega. Así Virgilio es equiparado a Homero, Salustio a Tucídides, Livio a Heródoto, Cicerón a Demóstenes, etc. En algunos géneros literarios, el rétor se lamenta de la ausencia de autores latinos que logren alcanzar la maestría de los escritores griegos: tal es el caso de la comedia, el yambo, la tragedia y la filosofía (10.1.99-123). Sin embargo, en otros géneros la producción literaria romana alcanza superioridad (sátira, 10.1.93) o al menos igualdad (elegía y oratoria, 10.1.93 y 105). Por otra parte y como adelantamos supra, en relación con los autores latinos opera una ruptura con el canon varroniano-ciceroniano (de cierto prestigio aún entre los académicos), que otorgaba gran importancia a los

eminentissimus, 10.1.46); Píndaro (princeps spiritu, magnificentia, sententiis, figuris, beatissima rerum uerborumque copia et uelut quodam eloquentiae flumine, 10.1.61); Alceo (tyrannos insectatus multum etiam moribus confert, in eloquendo quoque breuis et magnificus et diligens et plerumque oratori similis, 10.1.63); la comedia antigua Aristófanes, Éupolis y Cratino- (aut similior sit oratoribus aut ad oratores faciendos aptior, 10.1.65). Para el resto de los escritores, cf. supra el cuadro 1.

16 Quintiliano valora a Virgilio por ser proximus a Homero (10.1.85); de Lucano se dice que "debe ser imitado más por los oradores que por los poetas" (10.1.90); y de Horacio comenta, respecto de la poesía lírica, que plenus est iucunditatis et gratiae et uarius figuris et uerbis felicissime audax (10.1.96).

17 En el juicio sobre Julio César se encuentran muchas de las virtudes del orador: tanta in eo uis est, id acumen, ea concitatio...; exornat tamen haec omnia mira sermonis... elegantia (10.1.114). 
arcaicos. Así, Quintiliano se distancia u otorga poco interés a los escritores del período temprano de la literatura romana: Enio (10.1.88), Lucilio (10.1.94), Accio, Pacuvio y Plauto (10.1.97-99). Por el contrario, incluye a autores posteriores, especialmente a los augusteos -mostrando en este sentido una clara convergencia con las tendencias de la primera mitad del siglo I d. C.- e, incluso, se refiere a escritores latinos del Imperio en las secciones de épica, historia, oratoria y filosofía. No obstante, más allá de identificar estos criterios, una cuestión que llama nuevamente la atención es que no todos los autores incluidos en la lista son aprobados y recomendados para su imitación: por ejemplo, el poeta Ovidio recibe comentarios poco elogiosos en cualquiera de los géneros en los que se lo menciona $(10.1 .88,93,98)$, principalmente por su lasciuitas ${ }^{18}$.

Lo expuesto hasta aquí nos lleva a reflexionar acerca de la finalidad de este canon y del criterio de selección asociado a ella. Es evidente que el catálogo no se ha limitado exclusivamente a los mejores autores, dado que muchos reciben elogios matizados con observaciones sobre sus carencias o vicios. A modo de ejemplo, este es el caso de, entre otros, Arato, Estesícoro o los antiguos estoicos ${ }^{19}$, y entre los latinos -más allá del referido Ovidio- de varios poetas épicos y trágicos o de Séneca ${ }^{20}$. Además, reciben críticas muchos de los historiadores, especialmente los griegos, y prácticamente todos los oradores, exceptuados Demóstenes y Cicerón. Con todo, esto no debería llamarnos la atención, si tenemos en cuenta el siguiente pasaje:

Neque id statim legenti persuasum sit, omnia quae summi auctores dixerint utique esse perfecta. Nam et labuntur aliquando et oneri cedunt et indulgent ingeniorum suorum uoluptati... (10.1.24).

Y que no se persuada al lector de que todo lo que han dicho los mejores autores es necesariamente perfecto. En efecto, en ocasiones cometen deslices y ceden al peso de su propio talento y se entregan a satisfacerlo,...

18 Cf., también, Quint., Inst. 4.1.77. La lasciuitas es presentada como vicio desde el libro 2 (ver 2.4.4; 2.5.10; 2.5.22).

19 Critica a Arato porque tiene nulla uarietas, nullus adfectus, nulla persona (10.1.55), a Estesícoro porque redundat atque effunditur (10.1.62) y a los antiguos estoicos porque minus indulsere eloquentiae (10.1.84). Para el resto de los escritores, cf. supra el cuadro 1.

20 A modo de ejemplo mencionamos algunas críticas: Cornelio Severo (uersificator quam poeta melior,... uindicaret sibi iure secundum locum, 10.1.89), Accio y Pacuvio (nitor et summa in excolendis operibus manus defuit, 10.1.97) y Séneca (potioribus praeferri non sinebam, 10.1.126). Volveremos sobre este último más adelante. Para el resto de los escritores, cf. supra el cuadro 1. 
Podemos admitir entonces que, a pesar de sus fallas, los autores mencionados siguen siendo los mejores a imitar ${ }^{21}$. Incluso podríamos justificar la mención de aquellos a los que directamente aconseja no emular, si pensamos que un exemplum a veces funciona por similitud y otras enseña a partir de mostrar lo incorrecto. Este es el caso puntual de Séneca, a quien se le reconocen ciertos méritos (magnae uirtutes, 10.1.128), pero que en el campo de la filosofía aparece como el representante del estilo corrompido:

...sed in eloquendo corrupta pleraque, atque eo perniciosissima quod abundant dulcibus uitiis (10.1.129).

...pero en el estilo la mayoría de sus elementos son corruptos y muy perniciosos por esto: porque abundan en defectos seductores.

Por el contrario, no habría justificación aparente para ampliar la lista con otros autores de los cuales no se emite juicio alguno (se proporciona solamente el nombre sin indicación de sus cualidades). Tal es el caso de, entre otros, Tirteo (10.1.56), Calímaco y Filetas de Cos (10.1.58), o de Propercio y Persio (10.1.93-94). Igualmente, algunos son valorados solo dentro de su propio género, aunque no para la oratoria ${ }^{22}$. Este hecho nos permite aventurar que, según Quintiliano y al menos en lo referente a la enseñanza de la retórica, estos autores carecen de una utilitas específica, pero que, debido a su enorme prestigio al interior del campo cultural de la época, no podían estar ausentes del canon. De este modo, podría explicarse por qué se ha infiltrado la lírica, considerada, según vimos, como 'indecente'.

Así pues, podemos afirmar que el criterio de selección utilizado por Quintiliano se va difuminando a medida que avanza el listado: los autores aludidos no son siempre los mejores de cada género y menos aun los mejores a ser imitados por un orador. En todo caso, ese es el criterio de base, pero la norma ejercida por la tradición, y quizás el temor a la crítica de sus colegas, impulsa al rétor a completar -o al menos a ampliar- el catálogo con autores igualmente reconocidos, aunque no en el ámbito oratorio, sí en su propio género. De esta manera, lleva a cabo una tarea que excede su labor como maestro y teórico de retórica, en tanto se aboca a la compleja (re)construcción de una historia literaria recibida: ejerce sobre los materiales ofrecidos por la tradición una particular lectura, selección y disposición según criterios diversos (utilitas, cronología, calidad estilística, etc.), sometiéndolos al mismo tiempo a un juicio estético.

21 Cf. Schwindt (2000: 163-164).

22 Algunos ejemplos son: Arato y Teócrito (10.1.55), Varrón de Átace (solo valorado como traductor, al igual que en Séneca -cf. Ep. 56.6), Tibulo y Galo (10.1.93), Catulo y Furio Bibáculo (10.1.95), Plauto, Cecilio, Terencio y Afranio (10.1.99-100), entre otros. 
De este modo y volviendo a nuestra hipótesis, el objetivo central de este catálogo recibe un tour de force: la finalidad didáctica no es, pues, exclusiva, ni logra impedir que ingresen al canon de la Institutio Oratoria toda otra nómina de escritores muy fuertemente presentes en otros compen$\operatorname{dios}^{23}$. Para justificar este último aspecto, por consiguiente, es necesario considerar otros cánones que han servido como fuentes para este tratado, tanto anteriores como contemporáneos de Quintiliano.

\section{Las fuentes de Quintiliano}

El autor de la Institutio Oratoria se vale de una pluralidad de fuentes, tanto griegas como romanas, que forman parte, a su vez, de una extensa tradición retórico-literaria, de la cual el propio rétor hispano se encuentra imbuido. No obstante, brinda nuevos juicios de valor en relación con los géneros y obras que menciona en su catálogo, que surgen precisamente -según aludimos en los preliminares de este trabajo- de su propia postura crítica frente a los textos transmitidos como canónicos, pero también de la interrelación con otras historias literarias y cánones emergentes elaborados por otros escritores, pertenecientes a su vez a nuevas tendencias y movimientos literarios que polemizan entre sí.

\subsection{Las fuentes griegas}

En primer lugar, para los autores griegos Quintiliano retoma la tradición del canon establecido por los filólogos y gramáticos alejandrinos (Aristarco, Aristófanes de Bizancio, etc.), que en ocasiones son aludidos por el rétor. Con todo, se muestra libre de discutir sus preceptos, como se vislumbra en 10.1.59-6024. Lamentablemente, de ellos no poseemos más que referencias o fragmentos poco contrastables, y el hecho de que el autor se aleje en ciertas ocasiones de sus opiniones, nos obliga a buscar otros modelos.

Gran parte de la crítica considera como fuente principal del canon de Quintiliano el tratado Peri mimeseos (De imitatione) de Dionisio de Halicarnaso ${ }^{25}$, lo cual se debe a que las coincidencias entre ambos autores son abundantes ${ }^{26}$. No obstante, cabe aclarar que Dionisio solo puede ha-

23 Para ver cómo opera esta fusión de una tradición antigua con otra más reciente para la selección de autores, en especial de los trágicos, cf. Citroni (2006: 4-6).

24 Cf. Duff (1964: 321).

25 Acerca del extenso debate sobre la influencia de Dionisio de Halicarnaso en Quintiliano, cf. LAird (2006: 16, n. 38); Rutherford (1992: 360-362); Citroni (2006: 1, n. 1); Duff (1964: 321-2); y SCHWindt (2000: 166).

26 Ambos cánones organizan la producción literaria en torno a los géneros más prestigiosos -especificando los escritores más importantes y su utilidad para el orador-, y dejan de 
ber orientado a nuestro rétor respecto de los autores griegos, dado que no aborda en absoluto la literatura romana. Un profundo análisis de las coincidencias y distanciamientos entre el De imitatione y la Institutio Oratoria puede hallarse en J. Cousin. En consecuencia, no nos detendremos puntualmente en estos aspectos, sino en las conclusiones que surgen de la comparación de ambos cánones.

Cuadro 3: el canon de Dioniso de Halicarnaso

\begin{tabular}{|c|c|c|c|c|}
\hline & \multirow{2}{*}{\multicolumn{2}{|c|}{ Género }} & \multicolumn{2}{|c|}{ Autores griegos } \\
\hline & & & + & 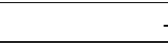 \\
\hline \multirow{5}{*}{$\begin{array}{l}\frac{\pi}{0} \\
\stackrel{0}{0} \\
0 \\
0\end{array}$} & \multicolumn{2}{|c|}{ Épica } & $\begin{array}{l}\text { 1.Homero } \\
\text { 2.Hesíodo } \\
\text { 3.Antímaco } \\
\text { 4.Paniasis }\end{array}$ & -- \\
\hline & \multicolumn{2}{|c|}{ Lírica } & $\begin{array}{l}\text { 1.Píndaro } \\
\text { 2.Simónides } \\
\text { 3.Estesícoro } \\
\text { 4.Alceo }\end{array}$ & -- \\
\hline & \multirow{3}{*}{ 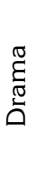 } & Tragedia & $\begin{array}{l}\text { 1.Esquilo } \\
\text { 2.Sófocles }\end{array}$ & 3.Eurípides \\
\hline & & Comedia antigua & "comediógrafos" & -- \\
\hline & & Comedia (nueva) & Menandro & -- \\
\hline \multirow{3}{*}{$\begin{array}{l}\mathbb{0} \\
0 \\
0 \\
0\end{array}$} & \multicolumn{2}{|c|}{ Historia } & $\begin{array}{l}\text { 1. Heródoto } \\
\text { 2.Tucídides }\end{array}$ & $\begin{array}{l}\text { 3.Jenofonte } \\
\text { 4.Filisto } \\
\text { 5.Teopompo }\end{array}$ \\
\hline & \multicolumn{2}{|c|}{ Filosofía } & $\begin{array}{l}\text { 1.pitagóricos } \\
\text { 2.Jenofonte } \\
\text { 3.Platón } \\
\text { 4.Aristóteles }\end{array}$ & -- \\
\hline & \multicolumn{2}{|c|}{ Oratoria } & $\begin{array}{l}\text { 1.Lisias } \\
\text { 2.Isócrates } \\
\text { 4.Demóstenes } \\
\text { 6.Hipérides }\end{array}$ & $\begin{array}{l}\text { 3.Licurgo } \\
\text { 5.Esquines }\end{array}$ \\
\hline
\end{tabular}

lado los géneros menores; el orden en que se presentan los géneros es prácticamente el mismo: primero se analizan aquellos que están en verso y separadamente los que utilizan la prosa; dentro de cada género, la nómina de autores mencionados y los juicios críticos emitidos sobre cada uno son bastante similares. Cabe destacar que ambos rechazan la literatura griega más reciente e incluyen casi solamente autores pre-helenísticos, siguiendo en esto a los filólogos alejandrinos. 
Es significativo notar que Quintiliano opera una ruptura respecto de esta fuente, principalmente en el hecho de adoptar el criterio jerárquico por sobre el cronológico, lo cual resulta más funcional al persuadere acerca de cuáles son los mejores autores; además, la lista de Quintiliano es más extensa porque admite géneros que Dionisio omite (como la poesía didáctica, bucólica, elegíaca o yámbica, o bien la comedia antigua) y añade autores helenísticos -rechazados ya por los filólogos alejandrinos; finalmente, en algunos géneros, como en el dramático -tanto comedia como tragedia- y en la oratoria, el alejamiento entre los críticos evidencia que ambos manejan fuentes diversas.

\subsection{Las fuentes latinas \\ 4.2.1 El canon ciceroniano}

Consideremos, en segunda instancia, a Cicerón. En el Brutus, M. Tulio se propone revisar toda la historia de la oratoria, desde sus orígenes hasta su propia época. Si bien mantiene el ordenamiento cronológico -tradicional en los cánones anteriores-, se ocupa de otorgar a cada autor una jerarquía fija y un determinado juicio de valor. Es decir que encontramos aquí, como adelantamos más arriba, el germen de la historia literaria que construye luego Quintiliano ${ }^{27}$. Más allá de lo formal, esta obra es además una fuente cierta para la constitución del listado de los rétores griegos.

Cuadro 4: el canon de Cicerón

\begin{tabular}{|c|c|c|c|c|}
\hline \multirow{2}{*}{ Género } & \multicolumn{2}{|l|}{ Autores griegos } & \multicolumn{2}{|c|}{ Autores romanos } \\
\hline & + & - & + & - \\
\hline $\begin{array}{l}\text { Poetas } \\
\text { (Orat., de } \\
\text { Orat.) }\end{array}$ & $\begin{array}{l}\text { Homero } \\
\text { Arquíloco } \\
\text { Píndaro } \\
\text { Sófocles }\end{array}$ & $\begin{array}{l}\text { Esquilo } \\
\text { Eurípides }\end{array}$ & -- & $\begin{array}{l}\text { Ennio } \\
\text { Accio } \\
\text { Pacuvio }\end{array}$ \\
\hline $\begin{array}{l}\text { Historia } \\
\text { (Orat., de } \\
\text { Orat.) }\end{array}$ & $\begin{array}{l}\text { 1.Heródoto } \\
\text { (princeps) } \\
\text { 2.Tucídides } \\
\text { (vicit) } \\
\text { 7.Calístenes } \\
\text { (rhetorico paene } \\
\text { more) }\end{array}$ & $\begin{array}{l}\text { 3.Filisto } \\
\text { 4.Éforo } \\
\text { 5.Teopompo } \\
\text { 6.Jenofonte } \\
\text { 8.Timeo }\end{array}$ & -- & -- \\
\hline
\end{tabular}

Continúa en la pág. siguiente

27 Acerca de la recepción por parte de Quintiliano de los criterios estético-literarios ciceronianos, cf. Doepp (1985); Alberte GonzÁlez (1998). Acerca del Brutus como historia literaria, cf. Fernández CoRTE - González MARín (2013). 


\begin{tabular}{|c|c|c|c|c|}
\hline $\begin{array}{l}\text { Filosofía } \\
\text { (de Orat.) }\end{array}$ & $\begin{array}{l}\text { 1.Sócrates } \\
\text { 2.Platón (1) } \\
\text { 3.Aristóteles } \\
\text { 10.Carneades }\end{array}$ & $\begin{array}{l}\text { 4.Jenócrates } \\
\text { 5.Antístemes } \\
6 . \text { Arístipo } \\
\text { 7.socráticos } \\
\text { 8.estoicos } \\
\text { 9.Arcesilao }\end{array}$ & -- & -- \\
\hline $\begin{array}{l}\text { Oratoria } \\
\text { (Brut.) }\end{array}$ & $\begin{array}{l}\text { 2.Isócrates } \\
\text { 3.Lisias } \\
\text { 4.Demóstenes } \\
\text { (perfectum) }\end{array}$ & $\begin{array}{l}\text { 1.Antecedentes: } \\
\text { Solón, Pisístrato, } \\
\text { Clístenes, Temís- } \\
\text { tocles, Pericles, } \\
\text { Cleón, Alci- } \\
\text { bíades, Critias, } \\
\text { Terámenes } \\
\text { 5.Hipérides } \\
\text { 6.Esquines } \\
\text { 7.Licurgo } \\
\text { 8.Dinarco } \\
\text { 9.Démades } \\
\text { 10.Demetrio F. } \\
\text { 11.Teofrasto }\end{array}$ & $\begin{array}{l}\text { 2.Galba (1 ), Le- } \\
\text { lio (2), Escipión } \\
\text { Afric., L. Cota } \\
\text { 6.Antonio, } \\
\text { Craso } \\
\text { 8.Sulpicio, } \\
\text { C. Cota } \\
\text { 10.Marcelo, CJ. } \\
\text { César } \\
\text { 11.Hortensio, } \\
\text { Bruto, Cicerón }\end{array}$ & $\begin{array}{l}\text { 1.Catón y con- } \\
\text { temp. } \\
\text { 3.or. medianos } \\
\text { contemp. al cír- } \\
\text { culo de Escip. } \\
\text { 4.Tib. Graco, } \\
\text { Carbón } \\
\text { 5.C. Graco, } \\
\text { Escauro, Rutilio, } \\
\text { Lut. Cátulo } \\
\text { 7. or. medianos } \\
\text { contemp. a Anto- } \\
\text { nio y Craso } \\
\text { 9.Pomponio, C. } \\
\text { Curión, Calidio, } \\
\text { Calvo y otros }\end{array}$ \\
\hline
\end{tabular}

Si observamos el tratado ciceroniano, a partir de la época de Isócrates (catálogo de oradores propiamente dichos) ${ }^{28}$, veremos que ambos autores coinciden en casi todos los nombres y sus calificaciones ${ }^{29}$. Es importante destacar la preponderancia de Demóstenes como modelo de orador, lo cual no solo se observa en Brutus (35), sino también en Orator (6) y de Oratore (1.58, 2.94, 3.28, etc.). En cambio, la fuente para el listado de los oradores romanos debemos buscarla en otro sitio, dado que Quintiliano elige no mencionar a ningún orador anterior a Cicerón (posiblemente por considerar que ya han sido detallados en el Brutus). Advertimos, entonces, que el recorte realizado por Quintiliano para el género oratorio se ha orientado a destacar los modelos por excelencia tanto de la oratoria griega (Demóstenes), como de la romana (Cicerón), lo cual es coherente con la finalidad formadora que plantea el rétor antes de comenzar el catálogo. Sin embargo, cabe destacar que, al momento de abordar los restantes oradores, el criterio utilizado para los griegos es diferente del empleado

${ }^{28}$ En su afán casi arqueológico por reconstruir propiamente el origen de la oratoria, Cicerón se remonta hasta Solón y Pisístrato, y recorre varios nombres de estadistas famosos por su elocuencia, como Pericles, e incluso de teóricos del arte retórico, todos los cuales no pueden ser considerados propiamente oradores.

29 A modo de ejemplo, compárese el juicio sobre Lisias en Brutus 35 y en Quint. Inst., 10.1.78. 
para los latinos: para los primeros, adopta sin cuestionamientos el canon de Marco Tulio -que no es más que el de Dionisio ampliado; mientras que para los latinos, decide ejemplificar con autores más cercanos a su época y, por tanto, más familiares para su alumnado. Esto no solo constituye una ruptura con Cicerón, sino específicamente con la tradición retórico-literaria de otorgar más valor a los escritores antiguos que a los modernos.

Si tomamos otros tratados de Cicerón, hallamos otras preferencias que comparte con Quintiliano: son interesantes, en este sentido, las figuras de Tucídides (de Orat. 2.56) y Arquíloco (Orat. 4), cuya valoración da cuenta de que ya $M$. Tulio había operado un cambio al menos respecto de Dionisio, quien prefería a Heródoto e ignoraba al yambógrafo. No obstante, otras diferencias de juicio con Cicerón evidencian finalmente que Quintiliano ha adoptado solo en parte el canon ciceroniano. Así, por ejemplo, se distancian respecto de los trágicos griegos (Orat. 4) y, en especial, de los autores romanos arcaicos. En este último punto, reiteramos, radica la mayor divergencia entre ambos críticos: el valor que conservan a fines de la República los antiguos -como Enio, Accio o Pacuvio (Orat. 36, de Orat. 3.27) - se ha diluido durante el primer siglo del Imperio.

\subsubsection{El canon augusteo}

En efecto, los críticos imperiales dirigen su mirada hacia los poetas consagrados en la época augustal (Virgilio, Horacio, Ovidio, etc.), no hacia los arcaicos y menos aun hacia los autores griegos anteriores a estos, de manera tal que podemos afirmar que polemizan con los cánones imperantes hasta ese momento. Este hecho nos lleva a indagar en el Principado a otros escritores latinos que pudieron influir en Quintiliano respecto de la valoración y jerarquización de ciertos autores. Algunos estudiosos ${ }^{30}$ coinciden en que también podemos hallar nuevas fuentes dentro de los géneros poéticos.

En este sentido y dada la ingente importancia que tuvo Horacio como crítico literario y la influencia de su Ars Poetica dentro de la tradición e historia literaria posterior ${ }^{31}$, no debe llamar la atención el hecho de que, al momento de construir su propio canon, Quintiliano haya sido influenciado por este, de cuyas Odas el rétor cita los elogios que el poeta dirige a Alceo o Píndaro.

30 Cf. Citroni (2006: 14-16); y Fontán (1974: 199).

31 Dado los límites del presente trabajo, y considerando que la teoría horaciana ha sido ampliamente desarrollada por la bibliografía crítica específica, remitimos a Harrison (2007) o a Kilpatrick (1990), entre otros; también a los ya citados Farrell (2010: 176-177 y passim); Fontán (1974: 205-210); Habib (2005: cap. 5); Laird (2006: cap. 15). 
Cuadro 5: el canon de Horacio (Ars Poetica y passim)

\begin{tabular}{|c|c|c|c|c|c|}
\hline \multirow{2}{*}{\multicolumn{2}{|c|}{ Género y subgénero }} & \multicolumn{2}{|c|}{ Autores griegos } & \multicolumn{2}{|c|}{ Autores romanos } \\
\hline & & + & - & + & - \\
\hline \multicolumn{2}{|c|}{$\begin{array}{l}\text { Hexámetros } \\
\text { (épica y bucólica) }\end{array}$} & $\begin{array}{l}\text { Homero } \\
\text { Tirteo }\end{array}$ & -- & $\begin{array}{l}\text { Polión } \\
\text { Vario } \\
\text { Virgilio } \\
\text { Varrón At. }\end{array}$ & Ennio \\
\hline \multicolumn{2}{|c|}{$\begin{array}{l}\text { Elegía } \\
\text { (poesía amorosa } \\
\text { en gral.) }\end{array}$} & no especifica & -- & -- & $\begin{array}{l}\text { Catulo } \\
\text { Calvo }\end{array}$ \\
\hline \multicolumn{2}{|c|}{ Sátira } & -- & -- & Horacio & Lucilio \\
\hline \multicolumn{2}{|c|}{ Yambo } & Arquíloco & -- & -- & -- \\
\hline \multirow{4}{*}{ 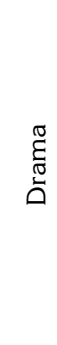 } & Comedia antigua & $\begin{array}{l}\text { Éupolis } \\
\text { Cratino } \\
\text { Aristófanes }\end{array}$ & -- & -- & -- \\
\hline & Tragedia & Esquilo & Tespis & -- & Accio \\
\hline & Comedia (nueva) & -- & -- & Fundanio & $\begin{array}{l}\text { Cecilio } \\
\text { Plauto }\end{array}$ \\
\hline & mimo & -- & -- & -- & Laberio \\
\hline
\end{tabular}

Asimismo, si examinamos las Sátiras -en especial la 1.4 y 1.10-, advertiremos que el rétor pudo haber tomado de aquí el canon de la comedia antigua (Éupolis, Cratino, Aristófanes) ${ }^{32}$ o los juicios negativos sobre Lucilio y otros arcaicos -como Enio o Accio-, e incluso un cierto desdén hacia Catulo y el mimo. En cambio, se mantienen en la mayor estimación Homero y Virgilio, siendo este último equiparado al primero. Si consideramos la obra crítica más importante de este poeta, el Ars Poetica, las coincidencias continúan. No podemos ahondar aquí en semejanzas a nivel teórico ${ }^{33}$, sino

32 Aquí se observa la mencionada ruptura con el canon de Dionisio, quien no alude a la comedia antigua y se centra solo en Menandro. Quintiliano retoma a los antiguos comediógrafos de la mano de Horacio y amplía la lista de la comedia Néa con Filemón.

33 Nos referimos en particular al respeto por las normas genéricas y al reconocimiento de las propias capacidades por parte de cada autor. Estos principios, fundamentales para que el producto artístico llegue a tener forma ("belleza", opuesto a deformis), se encuentran en amplia relación con el concepto de lo "adecuado" (aptum) que Quintiliano desarrolla a lo largo de todo su tratado, y que tanto él como Horacio toman de Aristóteles. Cf. Del Río SANZ (2002: 15). 
que nos detendremos más bien en el canon que puede desprenderse de la obra de Horacio a partir de la mención de los autores que se cuelan entre los versos del poeta. Aunque ambos críticos no acuerdan en todos los autores, se reitera la crítica a los arcaicos (Cecilio, Plauto, Enio) y llama la atención un relativo desprecio por la elegía al no personalizarla con el nombre de ningún autor destacado. Este podría ser un antecedente del rechazo que sufren la elegía y otros géneros líricos amorosos o satíricos, que el rétor considera 'inadecuados' por su lasciuitas. Debemos tener en cuenta que estas no son simples concurrencias, sino que poetas de envergadura del período augusteo dejaron sin duda una huella indeleble en la literatura latina, marcando tendencias críticas valoradas y retomadas en diversas épocas ${ }^{34}$.

Así como las sátiras horacianas son una fuente innegable para el canon de los comediógrafos antiguos, los poetas elegíacos, por su parte, proporcionan el canon de su propio género. En este sentido, Propercio señala reiteradas veces que sus fuentes griegas son Calímaco y Filetas de Cos $(2.140,2.34 .31-2,3.1 .1)$, tal como menciona Quintiliano. En cambio, discrepan en la valoración de Catulo y de Galo. Con todo, el influjo de este poeta sobre la opinión del calagurritano no se reduce a la elegía. En su poema 2.34, cobra interés el hecho de que entre los épicos nombra por supuesto a Homero, y añade a Hesíodo y Antímaco (los tres primeros que considera el rétor), olvidados en otras tradiciones; y entre los latinos no solo recuerda a Virgilio, sino también a Varrón de Átace -criticado, en cambio, por Horacio (S. 1.10.46).

Cuadro 6: el canon de Propercio (2.34 y passim)

\begin{tabular}{|c|c|c|}
\hline Género y subgénero & Autores griegos & Autores romanos \\
\hline Épica & $\begin{array}{l}\text { Homero } \\
\text { Hesíodo } \\
\text { Antímaco }\end{array}$ & $\begin{array}{l}\text { Virgilio } \\
\text { Póntico } \\
\text { Ennio } \\
\text { Varrón At. } \\
\text { (también elegía) }\end{array}$ \\
\hline Elegía & $\begin{array}{l}\text { Calímaco } \\
\text { Filetas }\end{array}$ & $\begin{array}{l}\text { 1.Catulo } \\
\text { 2.Calvo } \\
\text { 3.Galo } \\
\text { 4.Propercio }\end{array}$ \\
\hline Tragedia & Esquilo & -- \\
\hline
\end{tabular}

$\overline{34}$ Por ejemplo, el agregado de Pisandro, Nicandro, Euforión y Tirteo en el canon del rétor se debe a que son elogiados por poetas como Virgilio (Eclogae, 10.50) y Horacio (Ars Poetica, 401). 
Ovidio, por su lado, en sus famosos catálogos de los Tristia 2 y 4 establece, a su vez, un canon de poetas elegíacos romanos que difiere del properciano y que se asemeja mucho más al que señala Quintiliano. Incluso deja aparte a Catulo (aunque lo valora como poeta erótico, paradójicamente recurriendo al adjetivo lasciuus, utilizado por el maestro hispano con un valor semántico negativo, como ya señalamos), junto con una extensa lista de autores que alguna vez se dedicaron a la musa amorosa: Varrón de Átace, Cornificio, Tícidas y Cinna, a los que añade un grupo de poetas amigos suyos (la mayoría de los cuales solo son conocidos por esta referencia) ${ }^{35} \mathrm{y}$, además, toda una serie de oradores o estadistas que escribían elegías y epigramas en momentos de otium. Ovidio no solo eterniza a escritores contemporáneos de este tipo de poesía, sino también de todos los géneros que menciona. De este modo, se enfrenta a los preceptos de Cicerón y a la concepción tradicional de preferir a los antiguos escritores frente a los más recientes, polémica que mantendrá su vigencia -en favor de los nuevos autores- hasta inicios del siglo II d. C. Por otro lado, Nasón evidentemente toma la misma tradición que adopta luego Quintiliano en cuanto a la tragedia, ya que prefiere a Eurípides por sobre los otros tragediógrafos, a diferencia de Dionisio, Horacio y Propercio, que siguen un canon más antiguo que privilegia a Esquilo. Cabe destacar, asimismo, que Ovidio nombra además -al igual que el orador hispano- al poeta trágico Vario, hasta ahora no mencionado por ninguna otra fuente. No acuerdan, en cambio, respecto de los líricos griegos ni en la valoración de ciertos géneros menores ${ }^{36}$.

Cuadro 7: el canon de Ovidio (Tristia 2 y 4, Epistulae ex Ponto 4.16)

\begin{tabular}{l|l|l}
\hline Género y subgénero & \multicolumn{1}{c}{$\begin{array}{l}\text { Autores } \\
\text { griegos }\end{array}$} & \multicolumn{2}{l}{ Autores romanos } \\
\hline $\begin{array}{l}\text { Hexámetros (épica, poesía } \\
\text { didáctica y bucólica) }\end{array}$ & Homero & $\begin{array}{l}\text { Ennio (-), Lucrecio } \\
\text { Virgilio } \\
\text { Macro, Rabirio, Pedón } \\
\text { Marso, Póntico, J. Montano } \\
\text { y otros contemp. }\end{array}$ \\
\hline
\end{tabular}

Continúa en la pág. siguiente

\footnotetext{
35 Cf. Echavarren (2006).

36 Ovidio ensalza a Anacreonte y a Safo y agrega a su canon los "relatos milesios" (Tr. 2.413). Todos estos son ignorados por el autor de la Institutio Oratoria.
} 


\begin{tabular}{|c|c|c|c|}
\hline \multirow{2}{*}{\multicolumn{2}{|c|}{ Elegía }} & Calímaco & $\begin{array}{l}\text { 1.Galo } \\
\text { 2.Tibulo } \\
\text { 3.Propercio } \\
\text { 4.Ovidio }\end{array}$ \\
\hline & & & $\begin{array}{l}\text { Catulo } \\
\text { Varrón At. } \\
\text { Tícidas, Cornificio } \\
\text { Cinna, Catón (gram), } \\
\text { Hombres públicos (poetas ocasionales) } \\
\text { y otros contemp. }\end{array}$ \\
\hline \multicolumn{2}{|c|}{ Yambo } & -- & Baso (?) \\
\hline \multicolumn{2}{|c|}{ Lírica } & $\begin{array}{l}\text { Anacreonte } \\
\text { Safo }\end{array}$ & Horacio \\
\hline \multirow{2}{*}{ 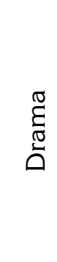 } & Tragedia & Eurípides & $\begin{array}{l}\text { Accio } \\
\text { Cornelio Sev. } \\
\text { Vario } \\
\text { y otros contemp. }\end{array}$ \\
\hline & Comedia (nueva) & Menandro & $\begin{array}{l}\text { Terencio } \\
\text { Melisso }\end{array}$ \\
\hline \multicolumn{2}{|c|}{ Rel. milesios } & Arístides & -- \\
\hline
\end{tabular}

Como conclusión parcial, notamos que los poetas del Principado han ejercido una importante influencia en los inicios de la época imperial, no solo en otros poetas que los imitan, sino especialmente en la crítica literaria, que retoma y normativiza las preceptivas poéticas de los autores a medida que acceden al reconocimiento popular.

\subsection{3 Época Imperial}

Como señalamos en la introducción y según evidencian las variables que despliega cada autor analizado, si el canon es algo dinámico, que se transforma según las necesidades de cada época, de cada escritor y de cada obra, es imposible que los contemporáneos no hayan influido en la visión que el rétor poseía de la literatura.

En consonancia con lo dicho, abordaremos primero la obra de Séneca, un poco anterior a Quintiliano y que, a pesar de ser muy criticado por este, coincide con él en muchos de los preceptos sobre el estilo, al me- 
nos teóricamente. A este respecto, resulta fundamental la carta 114 de las Epistulae Morales ad Lucilium, que se inscribe en la polémica de las causas de la corrupción de la elocuencia. En esta epístola, Séneca ataca la figura de Mecenas como modelo de la elocuencia corrompida y, a partir de allí, rechaza algunos aspectos estilísticos, negativos también para Quintiliano, como ser la concisa oscuridad -de la cual son modelos Salustio ${ }^{37}$ y su imitador Arruntio- contrapuesta al estilo de Tito Livio, o la lentitud que le adjudica al propio Cicerón en sus discursos ${ }^{38}$. Mención aparte merece el uso de arcaísmos: a este respecto encontramos cierta ambigüedad en las cartas, ya que si bien el epistológrafo se opone a la imitación de autores antiguos -tan valorados por Cicerón-, no obstante, en la epístola 58 se lamenta de la pérdida de vocablos y del empobrecimiento paulatino de la lengua latina, razón por la cual recomienda frecuentar, entre otros autores arcaicos, a Enio y a Accio, a diferencia de Quintiliano. Prevalece, de todos modos, el gusto por autores contemporáneos o recientes ${ }^{39}$. Finalmente, es más terminante que el rétor en relación con los poetas líricos, cuya lectura considera una pérdida de tiempo (49.5).

Cabe destacar también que a lo largo de las cartas Séneca nombra o cita una gran cantidad de autores, desde Homero hasta sus días. Entre las 'citas de autoridad' más frecuentes (empleadas como exempla filosóficos o morales) encontramos a Virgilio, Horacio u Ovidio, lo cual confirma la enorme importancia que habían adquirido los poetas augusteos poco después de concluir el Principado. Respecto de los griegos, cobra relevancia la coincidencia en otorgar a Eurípides el primer lugar entre los trágicos.

\footnotetext{
37 Ver nota 11.

38 Cf. Quint., Inst. 10.2.17, donde crítica a Cicerón por sus circunloquios. En todas las restantes cartas senecanas en las que se nombra a Cicerón, sin embargo, este es muy valorado, no solo como orador, sino también como filósofo.

39

Por ejemplo, menciona a Julio Montano (en 122, el cual había sido mencionado por Ovidio), o al poeta Valgio Rufo (51).
} 
Cuadro 8: el canon de Séneca (Epistulae)

\begin{tabular}{|c|c|c|c|c|c|}
\hline \multirow{2}{*}{\multicolumn{3}{|c|}{ Género y subgénero }} & \multirow{3}{*}{$\begin{array}{l}\text { Autores griegos } \\
\text { Homero } \\
\text { Hesíodo }\end{array}$} & \multicolumn{2}{|c|}{ Autores romanos } \\
\hline & & & & \multirow[b]{2}{*}{$\begin{array}{l}+ \\
\text { Virgilio (1 ) } \\
\text { Ennio } \\
\text { Lucrecio } \\
\text { J. Montano } \\
\text { Ovidio (Met.) } \\
\text { Cornelio Sev. } \\
\text { Messala } \\
\text { Varrón At. }\end{array}$} & \multirow{2}{*}{ Pedón } \\
\hline \multirow{7}{*}{$\begin{array}{l}\frac{\pi}{0} \\
0 \\
0 \\
0\end{array}$} & \multicolumn{2}{|c|}{$\begin{array}{l}\text { Hexámetros } \\
\text { (épica, poesía } \\
\text { didáctica y bucólica) }\end{array}$} & & & \\
\hline & \multicolumn{2}{|c|}{ Sátira } & -- & Horacio & -- \\
\hline & \multicolumn{2}{|c|}{ Lírica } & "Los nueve líricos" & -- & -- \\
\hline & \multicolumn{2}{|c|}{ Poesía ligera } & -- & Valgio Rufo & -- \\
\hline & \multirow{3}{*}{ 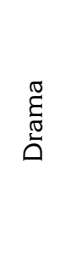 } & Tragedia & Eurípides & $\begin{array}{l}\text { Nevio } \\
\text { Accio }\end{array}$ & -- \\
\hline & & $\begin{array}{l}\text { Comedia } \\
\text { (nueva) }\end{array}$ & -- & Terencio & -- \\
\hline & & Mimo & -- & Pub. Siro & -- \\
\hline \multirow{3}{*}{\multicolumn{2}{|c|}{$\begin{array}{l}\pi \\
0 \\
0 \\
0 \\
0\end{array}$}} & Historia & -- & $\begin{array}{l}\text { T. Livio } \\
\text { Aufidio Basso }\end{array}$ & $\begin{array}{l}\text { Arruntio } \\
\text { Salustio } \\
\text { Tanusio Gém. }\end{array}$ \\
\hline & & Oratoria & -- & Cicerón & $\begin{array}{l}\text { A. Polión } \\
\text { Apio Cl. Ciego } \\
\text { Craso } \\
\text { Curión } \\
\text { Tib. Graco } \\
\text { Mecenas }\end{array}$ \\
\hline & & Filosofía & $\begin{array}{l}\text { Platón (1) } \\
\text { Aristóteles } \\
\text { Teofrasto }\end{array}$ & Cicerón & -- \\
\hline
\end{tabular}

Finalmente, para procurar también la perspectiva de los poetas de la época flavia, aludiremos a Marcial, quien sobrevivió a Quintiliano y que, para la época de la publicación de la Institutio Oratoria, ya había dado a conocer la mayor parte de su obra. Resulta de sumo interés su posición, ya que, en primer lugar, es realmente contemporáneo al rétor y porque, 
en segundo lugar, difiere completamente de aquel e, incluso, es ignorado por Quintiliano en su canon por dedicarse a un género poético considerado menor. Las referencias de Marcial a diversos escritores griegos y romanos, así como sus juicios de valor en torno a ellos, se hallan diseminados a lo largo de cientos de epigramas. Detallaremos aquí solamente algunos que resultan significativos para nuestro estudio.

Cuadro 9: Marcial: canon de autores en verso

\begin{tabular}{|c|c|c|c|c|}
\hline \multirow{2}{*}{\multicolumn{2}{|c|}{ Género }} & \multirow{2}{*}{ Autores griegos } & \multicolumn{2}{|l|}{ Autores romanos } \\
\hline & & & + & - \\
\hline \multicolumn{2}{|l|}{ Épica } & Homero & $\begin{array}{l}\text { Virgilio } \\
\text { Lucano } \\
\text { Domiciano (emp.) }\end{array}$ & $\begin{array}{l}\text { Ennio } \\
\text { Marso } \\
\text { Pedón } \\
\text { Cinna }\end{array}$ \\
\hline \multirow{2}{*}{ 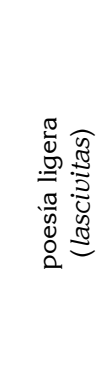 } & $\begin{array}{l}\text { Epigra- } \\
\text { ma }\end{array}$ & $\begin{array}{l}\text { Calímaco } \\
\text { Bruciano }\end{array}$ & $\begin{array}{l}\text { Catulo } \\
\text { Marso } \\
\text { Pedón } \\
\text { Marcial } \\
\text { y contemp. }\end{array}$ & -- \\
\hline & Elegía & -- & $\begin{array}{l}\text { Propercio } \\
\text { Galo } \\
\text { Tibulo } \\
\text { Catulo } \\
\text { Ovidio }\end{array}$ & Cicerón \\
\hline \multicolumn{2}{|l|}{ Sátira } & -- & $\begin{array}{l}\text { Persio } \\
\text { Lucilio }\end{array}$ & -- \\
\hline \multicolumn{2}{|l|}{ Lírica } & $\begin{array}{l}\text { Píndaro } \\
\text { Safo }\end{array}$ & $\begin{array}{l}\text { Horacio } \\
\text { Sulpicia } \\
\text { Nerón (emp.) } \\
\text { y contemp. }\end{array}$ & Nerva (emp.) \\
\hline \multirow{2}{*}{ 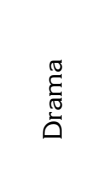 } & Tragedia & Sófocles & Vario & $\begin{array}{l}\text { Accio } \\
\text { Pacuvio }\end{array}$ \\
\hline & $\begin{array}{l}\text { Comedia } \\
\text { (nueva) }\end{array}$ & Menandro & -- & -- \\
\hline
\end{tabular}


Cuadro 10: Marcial: canon de autores en prosa

\begin{tabular}{l|l|l}
\hline Géneros & -- & \multicolumn{2}{l}{ Autores griegos } & $\begin{array}{l}\text { Salustio } \\
\text { T. Livio }\end{array}$ \\
\hline Historia & $\begin{array}{l}\text { Demócrito, } \\
\text { Zenón, } \\
\text { Platón, } \\
\text { Pitágoras }\end{array}$ & Séneca \\
\hline Filosofía & -- & $\begin{array}{l}\text { Séneca el rhétor } \\
\text { Cicerón } \\
\text { Plinio el Joven } \\
\text { Quintiliano } \\
\text { (moderator) }\end{array}$ \\
\hline & & motoria \\
& & \\
\hline
\end{tabular}

Es interesante detenerse en los Apophoreta o Libro 14. Todos estos poemas han sido escritos por encargo, y acompañaban -a modo de etiqueta- presentes que un señor regalaba a sus invitados en un banquete (por ejemplo, libros); de modo que no necesariamente reflejan la opinión de Marcial, pero sí los gustos estético-literarios de la época. Entre los epigramas 183 a 195 podemos encontrar etiquetas para obras de Homero, Virgilio, Menandro, Cicerón, Propercio, Livio, Salustio, Ovidio, Tibulo, Lucano y Catulo. Se observa, entonces, que las obras que circulaban en los eventos sociales de la época flavia se reducían, respecto de la literatura griega, prácticamente al autor que le dio origen y al exponente alejandrino de la Néa -que evidentemente mantiene un lugar primordial en el gusto popular; a su vez, respecto de la literatura latina, son privilegiados autores de la época augustal o del Imperio.

En el resto de los libros del epigramatista proliferan las referencias a diversos autores. Proporcionalmente, exceden en gran medida las de los latinos frente a las de los griegos, lo cual evidencia una preferencia opuesta a la del calagurritano. De enorme importancia para el estudio del canon de Marcial, resulta el poema 1.61, donde hallamos un catálogo de autores representados como canónicos o de indudable renombre: Catulo, Virgilio, Livio; Estela y Flaco (amigos del poeta); Apolodoro (autor desconocido); Ovidio, los dos Sénecas y Lucano; Canio Rufo, Deciano y Liciniano (otros amigos del poeta); y, por último, el propio Marcial. Como vemos, encabeza la lista el veronense y no azarosamente: no se puede dudar de que su obra ha inspirado al bilbilitano y el propio Marcial nunca lo olvida cuando defi- 
ne a sus antecesores epigramáticos latinos (5.5, 7.99). El segundo nombre, Virgilio, es el más reiterado en los 12 libros de epigramas ${ }^{40}$. Esto nos permite aventurar que, aparentemente, en esta época el autor de la Eneida es considerado un ícono literario, de igual modo que Homero lo es para la literatura griega. Cabe destacar que, observando el catálogo completo, el autor más antiguo que se menciona es Catulo; en contrapartida, proliferan los autores imperiales e incluso contemporáneos del epigramatista. Si tenemos en cuenta otros poemas, a esta lista se añaden Cornelio Galo (8.73), Horacio (1.107, 5.30, 8.18 y 12.3), Marso (2.71, 2.77, 5.5, 7.99), Pedón (2.77, 5.5), Persio (4.29), Propercio (8.73), Silio Itálico $(4.14,7.63,9.86)$, la poetisa Sulpicia -más estimada incluso que Safo en 10.35-, Tibulo (4.6, $8.70,8.73)$, el trágico Vario $(8.18,8.55)$ y una serie de poetas amigos de Marcial, desconocidos para nosotros. En géneros no poéticos, los filósofos griegos Demócrito, Zenón, Platón, Pitágoras (9.47), o Cicerón (3.38, 7.63, elogiado por sus habilidades oratorias) y Plinio el Joven (10.20). En todo Marcial, se encuentran muy pocas referencias a poetas griegos: Homero y Menandro (5.10), Sófocles (3.20), Píndaro (8.18), Safo (10.35) y sus antecesores en el género epigramático, Calímaco y Bruciano (4.23). Asimismo, debemos incluir el elogio a las composiciones poéticas de los emperadores romanos: tanto el epigramatista como el rétor incluyen la alabanza de los poemas épicos de Domiciano, lo cual responde también a la práctica del panegírico, muy desarrollada durante el Imperio ${ }^{41}$. Además de Domiciano, el bilbilitano (8.70) compara el estilo de Nerva y el de Nerón, a quien considera "el Tibulo de nuestro tiempo".

Son pocas las ocasiones en que, por el contrario, Marcial dedica espacio a criticar el estilo de otros autores y, cuando lo hace, generalmente sus ataques se dirigen a poetas contemporáneos de escasa estima -según la opinión del propio autor-, cuya única referencia son estos mismos versos. Ocasionalmente, sus víctimas son los arcaicos Enio (5.10), Accio y Pacuvio (11.90, rechazados por su rudeza), y el neotérico Cinna (10.21), a quien reprocha su oscuridad. Según se observa, la visión que subsiste del pasado literario romano es negativa, postura que reproduce la polémica 'antiguos vs. modernos', tan vigente en la época.

De esta revisión de los poemas de Marcial se desprenden ciertas características que reflejan las tendencias críticas del período. En primer lugar, la preeminencia de los escritores romanos, lo cual se relaciona con la mayor atención que durante el Imperio se dirige hacia los modelos latinos.

40 Se lo nombra directamente, o bien se mencionan sus obras, sus personajes o datos de su vida (Mantua, Mecenas, etc.). Sumando todas esas referencias es el autor más citado de los epigramas.

41 Marcial 5.5.7-8. Para la práctica del panegírico, cf. Plinio, Panegyricus; Vario Rufo, Panegyricus Augusti (poet. 5). 
Con todo, no podemos afirmar que Quintiliano comparta este punto de vista, dado que los griegos poseen una fuerte presencia en su canon. En segundo lugar, de estos modelos latinos todos los autores que el epigramatista valora -exceptuado Catulo- son del Principado o del Imperio, e incluso muchos escritores aludidos están aún vivos y son amigos del poeta. En esto Marcial se asemeja a los elegíacos, a Séneca y al propio Quintiliano, quien intercala en su canon, entre otros, a Valerio Flaco, Saleyo Basso, Pomponio Segundo, Servilio Noniano, Domicio Afro y, como ya señalamos, al propio emperador Domiciano.

\section{Conclusiones}

Según hemos expuesto al comienzo de este trabajo, mediante la elaboración de un canon, cada autor (re)construye en su obra y de una manera subjetiva una nueva historia literaria a partir de su singular lectura y (re)configuración de la tradición literaria recibida, así como a partir de su interrelación con las nuevas posturas crítico-literarias y cánones contemporáneos que circulan al interior del campo intelectual, que influencian a la vez que polemizan con las instituciones y con su propia producción artística.

En este sentido y de acuerdo con el recorrido efectuado, podemos extraer las siguientes conclusiones:

1. El canon de 10.1 posee una clara finalidad didáctica, que se justifica en el entramado discursivo como preámbulo a la teoría retórica de la imitatio desarrollada en 10.2. No obstante, en varios pasajes y, especialmente cuando aborda los autores latinos, Quintiliano no se restringe a emitir su opinión acerca de cuáles son los mejores autores y, especialmente, los más aptos o útiles para el estudiante de retórica. Por el contrario, alejándose del criterio de utilitas y de relevancia ${ }^{42}$ que guían la conformación de su canon, muchas veces incorpora autores con vicios de estilo remarcables o que se ubican en las antípodas de la teoría retórica desarrollada en los libros anteriores; o bien incluye a otros escritores que, aunque valorados en el género que practican, no aportan nada a la enseñanza del futuro orador; o bien hace referencia a géneros (por ejemplo, la elegía) que en otras partes de su tratado resultan, según el propio autor, hasta perjudiciales para el alumno. En consecuencia, consideramos que este abordaje de la literatura anterior y contemporánea excede propiamente su labor como magister y rétor, al tiempo que revela los intereses literarios de Quintiliano, más allá de lo específicamente retórico, permitiéndole formular algunas reglas generales y preceptos teóricos de crítica literaria.

42 Para una explicación del criterio de relevancia en relación con la práctica de la historia literaria, cf. FOWLER (2005: 266). 
2. La Institutio Oratoria de Quintiliano constituye un texto crítico y polémico que surge en el seno de una compleja realidad cultural donde proliferaban las formaciones discursivas acerca de lo que era la 'buena literatura'. Como pedagogo a la vez que historiador y crítico literario plantea un corpus canónico que, lejos de sostener el legado anterior, se presenta como singular y original ${ }^{43}$-razón por la cual no es posible encontrar una fuente unívoca-, fijando nuevas reglas expresadas por un inédito compendio de autores a imitar. De esta manera, el orador escapa a la norma y canon tradicionales (y, por tanto, a las constricciones ejercidas sobre él por la institución escolar a la que representa en tanto profesor de retórica oficial), al presentar una postura dialógica con los cánones y las recientes tendencias crítico-literarias que circulaban en la época, reflejando así el proceso de cambio cultural y el gusto literario de la misma.

3. Específicamente en el análisis de los cánones implícitos formulados por otros autores coetáneos, pudimos observar el hecho de que los cambios operados por Quintiliano respecto de las tradiciones anteriores se deben a las nuevas concepciones imperantes en la época, cuya característica principal es el respeto por aquellos escritores que sentaron las bases de la tradición, pero también la valoración e incorporación de las corrientes que afloraban. Así pues, en relación con los autores latinos realiza, por ejemplo, una ruptura con el canon varroniano-ciceroniano al desestimar a los escritores del período temprano de la literatura romana e incluir a autores posteriores, tanto augusteos como imperiales, lo cual es coherente con las predilecciones de sus contemporáneos, quienes coinciden con el autor de la Institutio Oratoria en las siguientes prácticas: la propia literatura romana adquiere un lugar central frente a la griega -que en épocas anteriores eclipsaba a la primera; se pone especial atención en los grandes autores augusteos, que reemplazan a los antiguos modelos; se renueva la concepción de lo 'canónico', puesto que ya no es necesario ser consagrado por la tradición previa para ingresar en un canon, sino que el gusto imperial se muestra favorable a autores recientes o vivos; por último, también se amplía el espectro genérico valorado ${ }^{44}$, a raíz de que en este período surgen autores que comienzan a destacarse en géneros antes poco explorados por los latinos, o que directamente producen una renovación en la literatura, siendo el caso de la novela o la silva.

43 En este sentido, Hinds (1998: 187) realiza la siguiente afirmación: “...an author's version of literary history is always itself, in critical practice, some reader's version of the author's version of literary history".

44 En la Institutio Oratoria no lo vemos en el canon del libro 10, pero sí en referencias aisladas a lo largo de otros libros. Cf. nota 12. 


\section{Bibliografia}

Alberte GonzÁlez, A. (1992) Historia de la retórica latina. Evolución de los criterios estético-literarios desde Cicerón hasta Agustín, Amsterdam.

Alberte González, A. (1998) "Recepción de los criterios retóricos ciceronianos en Quintiliano", en Albaladejo Mayordomo, T. - al. (edd.), Quintiliano: historia y actualidad de la retórica, Logroño, vol. I, pp. 159-184.

Alvarez, D. (1998) "Quintiliano, canon literario y poesía latina", en Albaladejo Mayordomo, T. - al. (edd.), Quintiliano: historia y actualidad de la retórica, Logroño, vol. II, pp. 881-890.

Beltrán Almería, L. -Escrig, J. (ed.) (2005) Teorías de la Historia Literaria, Madrid.

Citroni, M. (2006) "Quintilian and the perception of the system of poetic genres in the Flavian age", en Nauta, R. - Van Dam, H-J. -Smolenaars, J. (edd.), Flavian Poetry, Leiden-Boston, pp. 1-19.

Cousin, J. (1936) Études sur Quintilien. Tome I: Contribution a la recherche des sources de l' Institution Oratoire, Paris.

Cousin, J. (2003) Quintilien, Institution Oratoire. Tome VI: Livres X et XI, Paris, pp. 3-67.

Del Río Sanz, E. (2002) "Quintiliano y su idea del decorum: estilo, ética y retórica”, Berceo 143, pp. 11-20.

Depew, M. - ObBink, D. (edd.) (2000) Matrices of Genre. Authors, Canons, and Society, Cambridge.

DoEpP, S. (1985) "Cicero-Rezeption bei Quintilian am Beispiel von Inst. orat. 12.2.23-26", WS 19, pp. 159-171.

Duff, J. W. (ed.) (1964) A Literary History of Rome. In the Silver Age from Tiberius to Hadrian, London.

EchaVARREn, A. (2006) "Ovidio y dos poetas augústeos: Abronio Silón y Servilio Tusco", CFC 26.1, pp. 43-54.

FARRELL, J. (2010) "Literary Criticism", en Barchiesi, A. -Scheidel, W. (edd.) The Oxford Handbook of Roman Studies, Oxford, pp. 176-187.

Fernández Corte, J. C. -González Marín, S. (2013) "Escritura e historia literaria en el Brutus", Emerita 81.1, pp. 1-29.

Fernández, P. - Marello, E. (2010) "Quintiliano, Libro X, Inst. Orat. Reconfiguración de la tradición", en Vitale, M. A. - Schamun, M. (edd.), Actas del I Coloquio Nacional de Retórica "Retórica y Política" y de las I Jornadas Latinoamericanas de Investigación en Estudios Retóricos, Buenos Aires, pp. 1116-1122.

FontÁn, A. (1974) "Cicerón y Horacio, críticos literarios", EC 18.72, pp. 187-216.

Fowler, A. (2005) “Las dos historias”, en Beltrán Almería, L. -Escrig, J. 
(edd.), Teorias de la Historia Literaria, Madrid, pp. 253-271.

HabiB, M. (2005) A History of Literary Criticism and Theory. From Plato to the Present, Malden-Oxford-Carlton.

Harrison, S. (ed.) (2007) The Cambridge Companion to Horace, Cambridge. Hinds, S. (1998) Allusion and intertext: dynamics of appropriation in Roman poetry, Cambridge.

Kilpatrick, R. (1990) The Poetry of Criticism: Horace, Epistles II and Ars Poetica, Edmonton.

LAIRD, A. (2006) Oxford Readings in Ancient Literary Criticism, OxfordNew York.

PociÑA, A. (1981-2) "Quintiliano y el teatro latino", CFC 17, pp. 97-110

Pozuelo Yvancos, J. M. - Aradra Sánchez, R. (2000) Teoría del canon y literatura española, Madrid.

RutHeRFORD, I. (1992) "Inverting de canon: Hermogenes on Literature", HSCPh 94, pp. 355-378.

Schwindt, J. (2000) Prolegomena zu einer "Phänomenologie" der römischen Literaturgeschichtsschreibung. Von den Anfängen bis Quintilian, Göttingen.

Schwindt, J. -SchmiDt, E. (edd.) (2001) L'histoire litteraire immanente dans la poésie latine, Genève.

SullÁ, E. (ed.) (1998) El canon literario, Madrid.

TAVERNINI, N. (1953) Dal libro decimo dell'Institutio Oratoria alle fonti tecnicometodologiche di Quintiliano, Torino.

WiLLIAMS, R. (1980) Marxismo y literatura, Barcelona.

Winterbottom, M. (1992) M. Fabi Quintiliani Institutionis oratoriae libri duodecim, 2 voll., Oxford. 